\title{
Participated and Unparticipated Causes [and Forms] in Plotinus and Proclus
}

\author{
ISNS 2017 (Olomouc, CZ) — Panel: 'Form and Participation in Graeco-Arabic Neoplatonism' \\ Jonathan Greig (LMU-München, Munich School of Ancient Philosophy) \\ June 14, 2017 [Please do not cite without permission]
}

\section{Introduction}

Readers of Plotinus who start perusing Proclus may be surprised to find the concept of the 'unparticipated' posited: namely that the paradigmatic Form or entity ${ }^{1}$ for any set of members sharing the same essential property is unparticipated. This stands in contrast to both a standard Platonic reading of Forms and Plotinus' interpretation, whereby the Form (or again, entity) is directly participated. Proclus ends up transforming this framework by making the Form unparticipated—so, it is because the Form is unparticipated that the participants have their common property. As a corollary, what each participant participates is not the same for all, but unique to each. Thus particular A participates in participated form A; particular B in participated form B; and so on.

Given these two positions, it is not immediately apparent why Proclus posits the unparticipated in light of the traditional reading taken up by Plotinus. In other words, what motivates Proclus to posit the distinction? And in turn, what motivates Plotinus to restrict participation only to one common, separate Form? In his commentary on Proclus' distinction, E.R. Dodds thinks that both figures essentially share the same position, ${ }^{2}$ with Proclus carrying Plotinus' framework to its logical conclusion. ${ }^{3}$ However as I will show, while Dodds is in one degree right with Proclus' re-appropriation of the nature of transcendent Forms in Plotinus, his analysis is incorrect on the nature of participation from the participants' end: in Plotinus, the participants ontologically do not possess any distinct character that does not pertain to the transcendent Form; ${ }^{4}$ in Proclus, the participants rather do possess a distinct ontological trait—viz. the imminently participated form—in addition to the transcendent Form.

In what follows I will look at Plotinus' construal of participation with a focus on the case of sensibles. I will then look at Proclus' definition of participation and how his approach is both a critique and response to Plotinus' view, particularly in

\footnotetext{
${ }^{1}$ I.e. like Soul/World Soul, Intellect, or even the One; I briefly touch on these in the conclusion.

${ }^{2}$ In this I follow Chiara Russi's quip in Russi (2009) 147, likely with quotes like Dodds' here in mind: 'This, then, is the main point that I wish to develop in the present paper: the untenability of the hypothesis of a homogeneous Neoplatonism smoothly progressing from Plotinus to Proclus as if from the implicit to the explicit, from a simple (if ingenious) outline to a complete philosophical system. In the past, the practice of using Proclus as a criterion for the interpretation of Plotinus has meant that the divergences between these two philosophers have been regarded as mere exceptions to their general agreement.'

${ }^{3}$ See Dodds' commentary to Proclus, Elements of Theology, Prop. 23, in his trans./ed. (1963, Oxford University Press) p. 211: 'An approach to [the unparticipated/participated distinction] is already discernible in some passages of Plotinus; but Plotinus characteristically shrinks away from calling the transcendent term amethekton [i.e. 'unparticipated'] (cf. esp. Enn. VI.5.3), though it is ameriston ['partless'] and apathes ['unaffected'] —his mystical sense of the universe as the expression of a single divine force made the sharper distinction impossible for him. Proclus carries the thought to its logical conclusion.'

'Yet as will be briefly mentioned, this is not to say that there is no enmattered form or properties imminent in sensible matter. However Plotinus' emphasis on intelligible substance's domain as separate from what is divided and parted, with the sensible, factors in to his denial that the participant has a distinct intelligible form or property. Elaborated below.
} 
the case of participation for sensible objects. Our brief analysis may then give us a glimpse into why there are starker shifts in the higher levels for the two figures: the full separation of Soul from Intellect in Proclus, as 'fully descended'; the distinction between the unparticipated One and the henads; and so on.

\section{Plotinus on Participation, and the Participants as Mirrors of the Intelligible}

In Plotinus the specific discussion of participation comes up in depth in his discussion of Soul's relation to body 5 and sensible matter 6 in Ennead VI.4-5, titled 'On the Presence of Being, One and the Same, Everywhere as a Whole'. Steven Strange in his article on participation in Plotinus notes (I think correctly) that the whole treatise is implicitly concerned with addressing the sailcloth metaphor from Parmenides 131b-c and Plato's statement that the soul 'becomes divisible around bodies' in Timaeus $355^{7}$ Both imply difficulties if Soul, and thereby the Forms, are supposed to be whole, partless, immaterial, and 'everywhere' in relation to their several participants, ${ }^{8}$ or even for a given living body as a whole, compared to qualities which can pertain to one part of a body in relation to another. ${ }^{9}$

Plotinus first states his position on the nature of the Forms, or what he calls the 'All' (panta), in Enn. VI.4.2: as such, the All is altogether with itself as a whole, is everywhere, and exists in relation to nothing other than itself [T1 $].{ }^{10}$ By definition, Being exists as a whole in relation to whatever approaches it, and thereby Soul as well exists as a whole, rather than a part, to the living body. Plotinus' definition matches his basic position on the unity of the intelligible world, such that any given Form is strictly identified only within the realm in which it originates ${ }^{11}$ — that is, in Intellect's thinking itself. ${ }^{12}$ In the immediate context of the treatise, Plotinus uses this to consider how the 'All', or Being, can be 'stretched out' over extended space and volume, as between multiple bodies, or just over one given body. ${ }^{13}$ Here the sailcloth imagery from the Parmenides becomes relevant, illustrating the difficulty of conceptualizing the Form being a whole in relation to the participants which appear as 'parts', in one sense, though each receives the whole of the Form. The problem is then (1) how the Form remains whole and

\footnotetext{
${ }^{5}$ E.g. Ennead IV.1.

${ }^{6}$ E.g. Enn. II.4 and II.5, as well as in relation to matter's impassibility in Enn. III.6 ff. See Strange (1992) 480-1. Although one may wonder if Soul and its logoi enter in to the explanation for participation in Plotinus, at least in Enn. VI.4-5 this does not appear to be the main issue. See Strange (1992) 484-5: 'It has often been noted that VI.4-5 is remarkable in its failure to draw this distinction between the Idea and the soul-logos. But the reason for this must be that Plotinus does not see the distinction as being relevant to his purposes here. The activity of the soul through its logos in shaping matter is what we might call its "demiurgic" activity, having to do with the production of sensible properties: this would correspond to something like Aristotelian efficient causality. Participation, however, which is what Plotinus is concerned with in our treatise, corresponds rather to formal causality, that is, not to the explanation of how something comes to have a certain property, but rather to the explanation of what it is for it to have that property: here the productive or demiurgic activity of the soul does not enter into the explanation.'

${ }^{7}$ Strange (1992) 482, n. 12. For most of my interpretation I generally follow Strange's position in the article.

8See e.g. Enn. VI.4.1.

${ }^{9}$ Enn. VI.4.1, 18-29.

${ }^{10}$ Enn. VI.4.2, 1-6, 14-22: 'There exist certainly both the true All (to alêthinon pan) and the imitation of the All (to tou pantos mimêma), the nature of this visible universe. The really existent All is in nothing: for there is nothing before it. But that which comes after it must necessarily then exist in the All, if it is going to exist at all, being as much as possible dependent on it and unable either to stay still or move without it. [...] It is certainly not possible for the All, being all, to fall short of itself, but it exists as self-fulfilled and as a being equal to itself; and where the all is, there is itself: for it is itself the All. And altogether, if anything which is other than that All is set firm in the All, it participates in it and coincides with it and draws its strength from it, not dividing it into parts but finding it in itself as it itself approaches it without that All going outside itself; for it is not possible for being to be in not-being but, if at all, not-being in

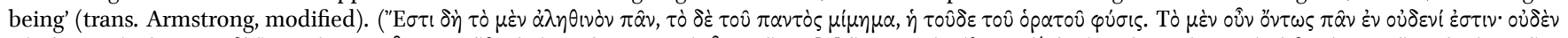

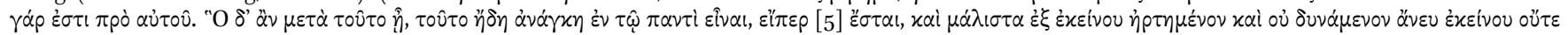

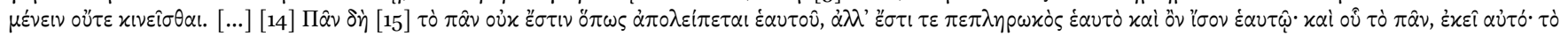

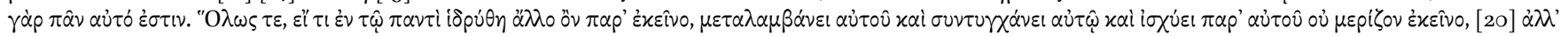

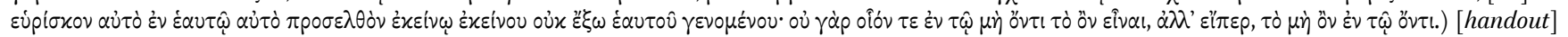

${ }^{11}$ See in general Chiaradonna (2014), esp. 223-4. As Chiaradonna notes, both intelligible and sensible being imply plurality, but what marks one from the other is the following: sensible being entails extension and parts being outside each other; intelligible being implies no extension, thereby no separation, and the 'parts' mutually entail each other, and so are 'inside' each other.

${ }^{12} \mathrm{~A}$ point I will briefly elaborate below, with Plotinus' view of substance motivating his stance on participation.

${ }^{13}$ See n. 10.
} 
'one' in itself, and (2) how it communicates itself, or is 'present' to the participants.

Plotinus' first response in Enn. VI.4.3 is telling for both these counts. He first brings up an 'intermediary' view, where 'powers' mediate between the Form and its participants_or in the example Plotinus cites, the Soul, while remaining itself, projects 'soul-rays' to particular living bodies, whereby the Soul is present through the 'rays' that are delegated. ${ }^{14}$ Plotinus' response is that this only pushes the problem backward, since powers are still essentially tied to their source [T2]:15

But where all the powers are, it [i.e. Soul] is itself clearly present, being in the same way separate; for if it became the form of this particular thing (toude eidos) it would have departed from being all and being everywhere in itself while belonging incidentally to another. But it belongs to no thing which wishes to belong to it, but as far as it can, approaches whatever it itself wishes, not by its coming to belong to that, nor again to anything else, but by the desire of that for it. There is nothing, therefore, surprising in its being in all things in this way, because it is also in none of them in such a way as to belong to them. ${ }^{16}$ (12-19; trans. Armstrong, modified)

Plotinus first sets out the difficulty for the intermediary position in three steps:

(1) powers belong to their respective recipients; yet,

(2) any given power is not separate from its source; therefore,

(3) the source of those powers, i.e. the Form, or Soul, also 'belongs' to each recipient.

The problem then becomes the Form as 'belonging' to the participant: if it belongs to one, then it is only 'incidentally' (kata sumbebêkos) related to its other participants. In stating this, one should see how Plotinus uses 'belonging' in an exclusive sense: if the Form belongs to one particular, it will not belong to another; instead, if the Form belongs to all its participants, then it can not be 'in' any specific one. In this respect, Plotinus takes the sailcloth aporia seriously, but instead of finding a solution with the metaphor, as with the 'powers' example, he ends up denying the whole/part dichotomy that is implied in the aporia: ${ }^{17}$ each participant still receives the whole of the Form, regardless of the partition implied with the sailcloth. However the Form's presence to the participants does not come from its end, but rather from the participants' end to the Form-in other words, the participatory action comes from the participants. ${ }^{18}$ Plotinus emphasizes this point further on when he refers to the 'day' metaphor for the Forms from Parm. 131b, saying that the Form must not be conceived as light 'proceeding' to the participants, but is the light itself which is participated by the participants. ${ }^{19}$ In this way, the Form (and thereby Soul) is the final cause for its participants, and even more strictly it is the formal cause for its participants. ${ }^{20}$

The unique consequence of this position is that the participants do not 'receive' anything from the participated Form, but merely reflect properties that pertain to the single Form (or in this case Soul). Plotinus is emphatic on this point: if intelligible

\footnotetext{
${ }^{14}$ Enn. VI.4.3, 1-6: 'Are we then going to maintain that it is present itself, or that it is on its own but powers form it come to all things, and this is why it is said to be everywhere? For in this way they say that the souls are like rays, so that it is set firm in itself but the soul-rays sent out come now to one living thing and now to another.' (trans. Armstrong).

${ }^{15}$ Cf. Strange (1992) 490 .

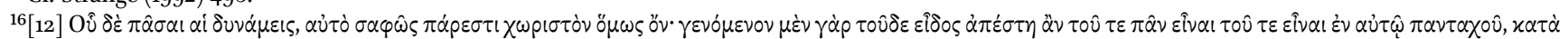

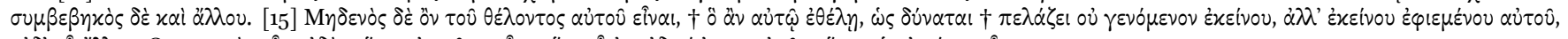

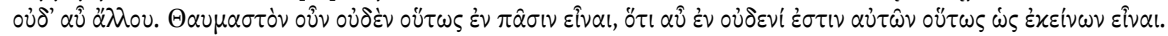

${ }^{17}$ Strange (1992) 481: 'Note that the commentators to whom Plotinus is responding in [Enn.] VI.4-5 all seem to treat the sailcloth dilemma as an aporia to be solved, rather than as a destructive attack on the Theory of Ideas.'

${ }^{18}$ As Strange (1992) 492 notes well, Plotinus' language here follows Plato in Phaedo 75 b with the mention of sensible equal things 'striving' (oregetai) to be like the Equal-itself.

${ }^{19}$ Enn. VI.4.4, 7,23-8,8. Cf. Strange (1992) 490-1.

${ }^{20}$ See n. 6.
} 
entities remain in themselves and not in another, then they cannot belong to, or be in, anything else other than themselves. One sees this when Plotinus brings up the example of the 'immaterial triangle' vs. instances of the triangle in matter [T3]:

But it [i.e. the intelligible/Form] is present the same in number everywhere, not like the triangle in matter which is multiplied by being in many, but like the immaterial triangle itself from which those in matter derive. Why then is not the triangle in matter everywhere, if the immaterial triangle is everywhere? Because not every matter participates in it, but every matter has something different, and not every matter is suitable for every Form. For even prime matter is not all adapted to every Form, but to the primary kinds [of bodily Form] and then others upon them. Form is certainly in some way present to everything. ${ }^{21}$ (VI.5.11, 31-38; trans. Armstrong)

So in this case, matter's capacity to 'receive', or rather reflect, the Form is both what makes it possible for it to be a participant, as well as to account for the variations and multiple instantiations of the same Form. The key here is that there is no extra element, like the form-in-matter_-specifically like an Aristotelian intelligible form-which conveys the separate Form to the matter, but merely a given matter's receptivity. ${ }^{22}$ Instead forms-in-matter and all sensible properties, while in one way the result of Soul's reason-principles (logoi) generating them, are yet mimêmata (imitations) or 'false' appearances. ${ }^{23}$

An indication of Plotinus' latter stance is his position on matter's impassivity as the final element in procession from the One through Intellect and Soul. As such, matter does not receive molding or a distinct shape, as 'enmattered form' would directly imply, since matter's nature repels any definition or form as pure privation. ${ }^{24}$ Plotinus' use of the mirror analogy in Enn. III.6 is applicable here [T4], wherein the reflection seen in the mirror appears to be a 'real', distinct object compared to the original subject of the mirror; however, the mirror does not change in itself if the subject walks in front of, or away from, the mirror. ${ }^{25}$ The mirror then 'participates' simply by reflecting its subject, and matter's impassivity in relation to participation

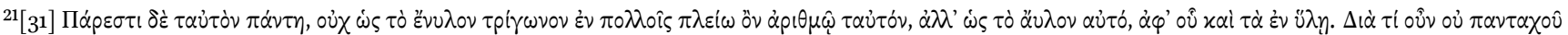

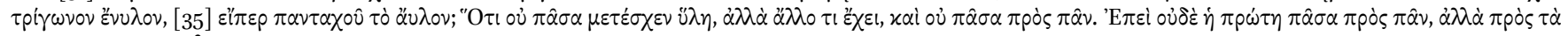

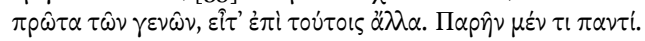

${ }^{22} \mathrm{Of}$ course this is said with respect to matter in itself, and not 'proximate matter', which Plotinus considers. See Strange (1992) 492, esp. n. 46: 'It might be thought that Plotinus is faced here with a version of the well-known problem about which came first, the chicken or the egg, since participants must already exist and thus already have some actual properties before they can enter into participation relations, yet the existence of actual properties was supposed to be accounted for by appeal to participation. ... This however does not seem to be a problem if the sort of participation under discussion is supposed only to account for sensible properties, since Plotinus thinks that prime matter, which is not a sensible thing, together with its (non-sensible) capacities for participation in size or extension (cf. II.4.8-10; III.6.16-18), is produced by soul prior to its producing anything of the sensible world (III.4.1), and that what is produced by prime matter thus participating are the extended masses of the physical elements, which then serve as hylomorphic matter for, i.e., participants in, successively higher levels of form. The actual properties of the participant at each stage of this hylomorphic layering are presumably what determines its capacity for further participation, e.g., color can only be participated by a surface. The problem remains, however, to account for why at the initial stage of information different parts of prime matter or the Receptacle are informed by different ones of the four physical elements. But Plato had already treated this as a brute, unexplained fact (Timaeus $52 \mathrm{~d}$ ).'

${ }^{23}$ See Strange (1992) 493, and esp. Van Riel (2001) 136-7: 'The last product of the emanation, i.e. matter, brought forward by the soul, is not capable itself of turning itself to its producer. This means that any determination will have to be imposed on the substratum. In other words, the soul will have to deliver a second effort. After having produced the substrate, the soul has to turn back to the lower stage, in order to bring beauty and form in it [Enn. IV.3.10, 2O-42]. The determination, then, remains entirely external to the substratum: as we have seen before, matter's indeterminacy is not extinguished by the soul's imposition of forms, it just undergoes it without losing its own nature.'

${ }^{24}$ On matter as pure privation, see Enn. III.4.1, 8-14-note esp. the distinction where matter, as purely indefinite, is unable to turn to its producer, whereas the higher producers (including Form and Soul's logoi) are defined as able to turn toward their higher causes, and therefore are definite in that sense. See also Van Riel (2001) 129-32, 136-7; De Haas (1997) 255-6; Opsomer (2001) 162-4. Although it appears that Plotinus absolutely rejects the notion of Aristotelian 'enmattered form', he still appropriates the language in his construal of sensible objects: see Karamanolis (2009) for a reconstruction. See also the significant proviso in Chiaradonna (2014) 224-5: 'The Peripatetic distinction between differentiae and accidents tends to vanish in Plotinus' physical world and sensible particulars emerge as mere 'conglomerations of qualities' which the causal activity of the logos (their intelligible forming principle) produces in matter (Enn. VI.3 [44].8.27-37; VI.3 [44].15.24-38). Elsewhere, however, Plotinus appears to hold a different position, since he establishes a hierarchy between constituent and accidental properties within sensible particulars and maintains that constituent features are activities that derive from the logos, whereas accidents have a different origin (which Plotinus however does not specify) (see esp. Enn. II.6[17].2.20—26). While some ingenious attempts have recently been made to reconcile Plotinus' accounts of the status of sensible particulars, I am inclined to think that the question must remain open (here Chiaradonna references Karamanolis 2009). It is difficult to avoid the impression that Plotinus' accounts reveal an internal tension, for either he is conceiving of sensible particulars as endowed with an internal structure, which corresponds to a hierarchical order among their properties (but this comes too close to the notion of 'essential property', and according to Plotinus sensible particulars are not endowed with essences), or he is conceiving of sensible particulars as integrally unstructured and qualitative wholes, where 'completing' and 'extrinsic' properties cannot be opposed (but this apparently jeopardizes an adequate explanation of sensible particulars, and Plotinus does not appear willing to abandon the idea that some properties are more 'important' than others).'

${ }^{25}$ See esp. Enn. III.6.13, 43-55, esp.: 'If, then, there really is something in mirrors, let there really be objects of sense in matter in the same way; but if there
} 
in Forms would then function similarly.

Now given this, I should note that Plotinus does imply in places that the Soul-trace and Soul's 'shadow' functions like an intermediary in conveying life to the body. ${ }^{26}$ At times he seems to give priority to enmattered form over other sensible qualities, though he also qualifies such form as another 'quality.' ${ }^{27}$ I admit this is a difficulty in squaring with these previous passages, and following Ricardo Chiaradonna, ${ }^{28}$ I think it leaves an internal tension in Plotinus' approach-issues that unfortunately the time and scope of this paper limit me in addressing. Suffice to say, I still follow Steven Strange's formulation in calling the properties perceived in matter, 'relations of participation' between sensible matter and the Forms, ${ }^{29}$ so that it does justice both to the mirror analogy and gives a kind of objectivity to the reflections in the mirror.

To summarize, Plotinus emphasizes the unity of the intelligible world to such a degree that he denies that participants receive any real, ontologically distinct components from the Forms. This informs his position of a strict two-tier structure of participation, between the separated, transcendent Form (as well as Intellect, or Soul) and the multiple participants. An overarching background to Plotinus' view here is his stance against the Aristotelian notion of substance, whereby attaining a definition and grasp of substance means that one can only truly find it in the realm of Intellect, and definitively not on the material level. As such, Plotinus denies the predication of substance on the material level, which further contributes to his position on the relation between the participants and the participated Form.

\section{Proclus on Participation, and the Unparticipated as Source of the Participated}

Turning now to Proclus, we find that he largely incorporates much from Plotinus' requirements about the nature of intelligible entities and transcendent Forms - however, not as directly participated, but as unparticipated (amethekton). We may see his position succinctly put in Prop. 23 in the Elements of Theology [ $\left.\mathbf{T}_{5}\right]: 30$

All that is unparticipated (to amethekton) produces out of itself the participated (ta metechomena); and all participated substances are linked upwards to subsistences (huparxeis) not participated.

For the unparticipated, having the account (logon) of a monad-as belonging to itself (heautou on) and not to another, and as transcending the participants_-generates from [itself] entities which are able to be participated. For either it will have been established as infertile according to itself, and would then have no honor, or else it will give something $(t i)$ from itself: on the one hand, that which receives (to labon) participates, while that which is given is brought to existence (hupestê) as what is participated.

is not, but only appears to be something, then we must admit, too, that things only appear on matter, and make the reason for their appearance the existence of the real beings, an existence in which the real beings always really participate, but the beings which are not real, not really' (trans. Armstrong). (Taútn

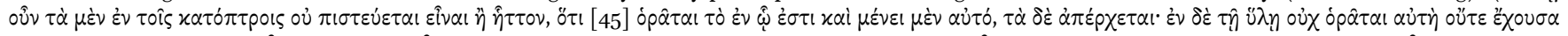

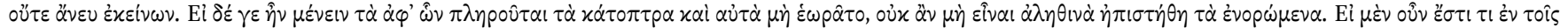

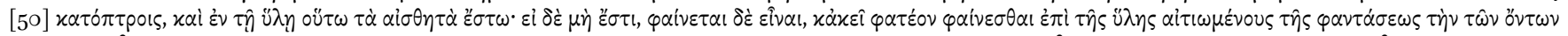

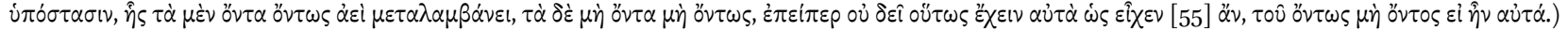

${ }^{26}$ For the trace, see Enn. IV.4.18, (esp. lines 1-9, 31); Enn. VI.4.15 (esp. line 15). For the relation of the 'trace' to an interpretation of enmattered form, see in particular Noble (2013) (esp. 25-6), with a differing interpretation in Caluori (2015) 186-92 (esp. 190-1) equating the Soul-trace with the activities (i.e. sensible qualities?) associated with life in the body. Unfortunately neither (as far as I can see) address their interpretation in light of this predominant issue of participation between impassive matter and the Forms.

${ }^{27}$ See Karamanolis (2009 $\mathrm{x}$ ) and Chiaradonna (2014) 224-5, and esp. n. 20.

${ }^{28}$ Chiaradonna (2014) 225 .

${ }^{29}$ Strange (1992) 494, although see the proviso in n. 50 regarding Denis O'Brien's thesis that prime matter in no way participates in the Forms. With Strange, this would be a problem for his qualification of 'relations of participation'. At the same time, the terminology behind the 'shadow' and 'trace' of Soul and the Forms in matter becomes problematic, especially when Plotinus emphasizes their distinct, sensible traits in matter in explicit contradistinction to the intelligible level. I must admit I so far don't see how these ambiguities can be resolved.

${ }^{30}$ See also In Parm. 709,17-710,7 (Steel), where the distinction is raised as a third, 'more theological' method of showing the priority of unity/the One to plurality/Being. 
Every participated entity, on the other hand-becoming that which belongs to a given particular (tinos genomenon) by which it is participated-is secondary to that which is present to all in the same way and fills all things from itself. For that which is in one is not in the others, while that which is present to all in just that way, in order that it may illuminate all, is not in one entity, but before all of them. For either (a) it is in all, (b) in one among all, or (c) before all. But (a) that which is in every object, being divided into every one [of them], would again be in need of another entity which unites that which has been divided (tou to meristhen henizontos) - and further all things would not participate in the same thing, but one entity in one, another in another, since its unity has been partitioned out (meristhentos). (b) If it is in one among all, it will yet not belong to all of them but to one. (c) And if it is then common to those entities which are able to participate, and is the same which belongs to all (pantôn), it will be before all; and this is the unparticipated. ${ }^{31}$ (trans. mine)

In Proclus' definition of participation, we can see both an affirmation of aspects, and an implicit critique, of Plotinus' framework. First, what Proclus defines as 'unparticipated' (amethekton) shares much of the same requirements that Plotinus holds for intelligible entities, like Soul and the Forms: it is a 'monad' which belongs only to itself, is 'present' to all its participants by being before them (pro pantôn); it 'belongs' to all participants by not being in any, or all, of them, and so on. Where Proclus diverges from Plotinus is in asserting that the unparticipated must 'give' something of itself to fulfill its function. In Plotinus, the Form does not 'give' anything — rather it is in virtue of not giving that the Form can be participated. Yet Proclus uses striking terms against this conception: if the Form (or entity) does not give anything, it is 'infertile' and even 'loses honor'. While in Plotinus one might say that the Form 'gives' to the participants, in a manner of speaking, it only provides 'appearances' (mimêmata) in the matter, as we saw. By comparison, Proclus says that that which the Form gives attains existence (hupestê) as a specific participated entity or property. ${ }^{32}$ On this point, Proclus appears to move against the appearance-only position from Plotinus by giving an ontological role, albeit subordinated, to the entity or property 'given' by the Form, which substantially changes the picture of participation we had from Plotinus. ${ }^{33}$

To be fair, Proclus still affirms Plotinus' ultimate point that the Form's 'content' (as it were) is only found apart and separate from the participants. Although one may be tempted to equate the Form's being separate with being 'unparticipated', as E.R. Dodds implies, the choice in terminology stems from a basic divergence on just what the participants participate: either for Plotinus, it is the same Form (or entity) as any other given participant; or for Proclus, the particular form (or entity) belonging only to that participant. If one holds the latter, then Proclus' argument for an extra tier with the 'unparticipated' makes sense inasmuch as one can hold both the primacy of the transcendent Form and the distinct, ontological existence of participated entities (i.e. imminent/enmattered forms, or individually separate souls, etc.).

A case in point is Proclus' commentary on Timaeus 31c-32a, on the proportion between the elements in the universe, where Proclus gives a physical interpretation of the 'proportion' spoken of in the passage. ${ }^{34}$ In the commentary, Proclus con-

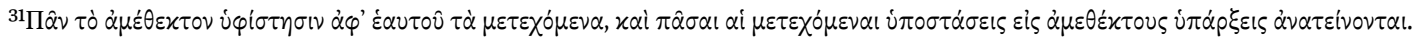

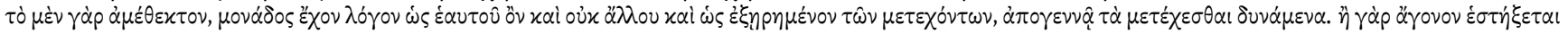

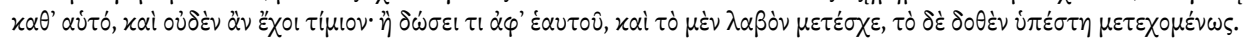

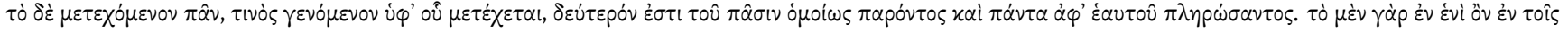

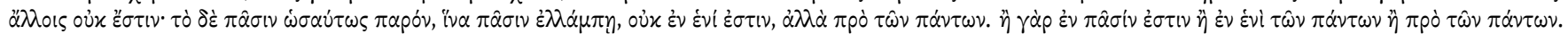

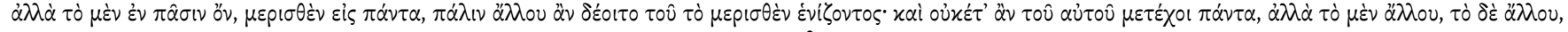

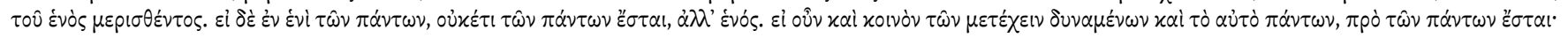

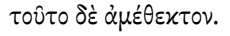

${ }^{32}$ Although 'what' is given is either a separately-existing entity (e.g. a particular soul for a given living body), or an imminent property (e.g. enmattered form); see ET Prop. 81-82. For now, esp. in keeping parallel to Plotinus' case examples, I stick with the latter for examples of participation in Proclus.

${ }^{33}$ Here I would take Proclus' affirmation of the principle of aph' henos kai pros hen in In Parm. 709,7 (Steel) as another sign of a positive affirmation of Aristotelian enmattered form (see e.g. Aristotle, Metaphysics Г.2, 1003a33-b13). Although as has been pointed out, Proclus (via Syrianus: cf. In Met. 58 ,24 ff.) takes a different interpretation from Aristotle: pros hen refers to the common notion post re, for the latter; for the former set, pros hen refers to the monad/Form/entity ante re.

${ }^{34}$ Begun from In Tim. II, 23,9 ff. Proclus provides the 'physical' interpretation as the lower extreme to the intelligible as the other extreme and the mathematical as a mean - here following a Pythagorean interpretation.
} 
nects enmattered form, which he calls 'physical number', with the ousiai that are divided about bodies, mentioned in Tim. 31c5. He then goes on to show how the enmattered form, which is partless, produces extension and divided powers in a given body [T6]:

For the form is one thing, but the power that derives from it is another. The form is partless (amerês) and substantial (ousiôdês), but once it has taken on extension and volume, it sends forth from itself the enmattered power like an exhalation (pnoe) and this is a particular quality. Take fire for example. The form of it and its substance is partless, since it is the genuine representation (agalma) of the cause of fire (for there is something partless among the things which have parts [Arist., Metaph. 968a2]). But though it [proceeds] from the form in a partless way, in the fire there comes to be an extension and interval associated with the matter. For essences do not come from qualities, neither are essence and power the same thing, but rather everywhere the essential (to ousiôdes) comes before the power. From this one thing [i.e. the essence] proceed a plurality of powers, and from the indivisible [essence there come to be] divisible [powers]. ${ }^{35}$ (In Tim. II, 25,5-19; trans. Baltzly, modified)

One should notice that whereas Plotinus would have identified the 'partless element' with the transcendent Form, as apart from the body, here Proclus ties it directly to the body in which the plurality of powers and qualities come forth. At the same time, Proclus links the enmattered form with the transcendent Form, which we can see with the fire example when Proclus says that the enmattered form of the fire is a 'genuine representation' of fire's 'cause' (aition). ${ }^{36}$ By implication, the latter 'cause' would reference the unparticipated Form of 'fire', while the enmattered form would be the participated component since it is a 'representation' of the cause. Another difference from Plotinus is when Proclus says that qualities must be posterior to essence (ousia), which implicitly counters Plotinus' claim in Enn. VI.3.8 that sensible ousia is a conglomerate of qualities. ${ }^{37}$ In the latter case, Plotinus works from the premise that true substance/ousia is only found in the intelligible realm, while at the sensible level what appears as 'substance' is only a conglomeration of properties which are all shadows and reflections of the transcendent Forms - as we saw earlier. For Proclus this is insufficient: sensible properties, albeit dispersed and plurified, still require an imminent organizing principle, one that is not just another quality alongside other qualities—hence Proclus' assertion of an imminent ousia prior to the properties.

While this is an example just on the material level for the participant/participated relation, ${ }^{38}$ it is generally indicative of why Proclus posits an intermediate, participated tier, and why he says that the unparticipated Form generates participated forms (or generically, entities) that belong to the participants. Whereas Plotinus holds to a strict definition of 'substance', Proclus (following Porphyry and Iamblichus) ${ }^{39}$ allows for a secondary, derived level of 'substance' that corresponds to specific, respective participants. Proclus' conception informs the way he sees the mirror analogy from Plotinus: although he agrees with the essential point, he disagrees with Plotinus' interpretation that matter remains impassive and merely shows reflections. Instead Proclus uses another analogy, that of images (eikones) made by painting or sculpture $\left[\mathrm{T}_{7}\right],{ }^{40}$ which indicates

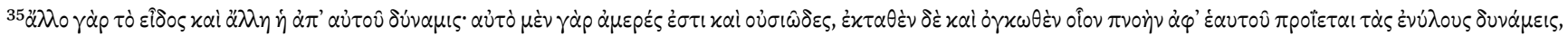

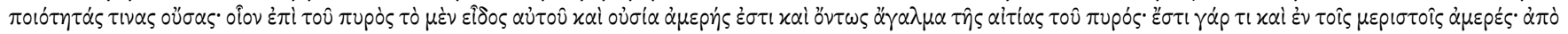

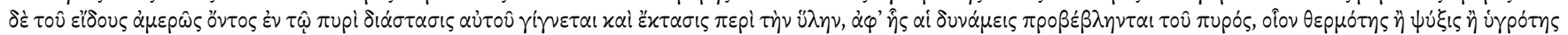

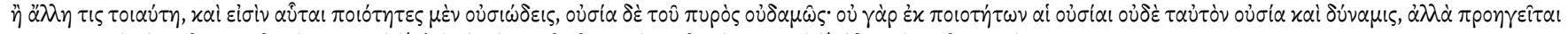

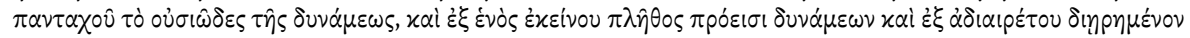

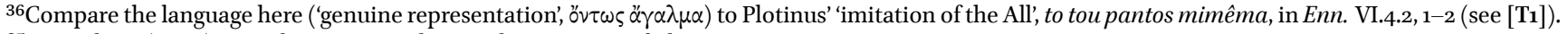

${ }^{37}$ See Helmig (2006) 272, who notes Proclus' implicit critique of Plotinus.

${ }^{38}$ Leaving aside here cases of participated souls, intellects, and henads (participated counterparts to the One, which is unparticipated) in Proclus' system. The argument here, however, carries over by analogy.

${ }^{39}$ Chiaradonna (2014) 225-7; see n. 32.

${ }^{40}$ The same example occurs in Plotinus, Enn. VI.4.10, $5^{-16}$, although there Plotinus emphasizes that it is only the 'this particular disposition of colors' which composes the likeness painted. Plotinus considers this as an objection to his view of participated properties in sensibles, viz. that the painting can still exist once the subject has walked away. Thus he seems to subordinate the example to his preferred imagery of the mirror. If true, then it is much more striking that Proclus reverses the priority: he deemphasizes the mirror example, and prioritizes the painting example.
} 
both the subject's reflection as well as the distinct shaping in the matter. ${ }^{41}$ At base Proclus' critique again reflects his general distinction between the unparticipated and participated, with the Form remaining unparticipated and the imparted shape, like the painting or sculpture, as the participated aspect. What is then imparted is not just a reflection in matter, as Plotinus, but an intelligible principle that is imminent within the matter.

Before concluding, it is noteworthy that Proclus does not directly criticize Plotinus for failing to hold the unparticipated/participated distinction (while apparently he does over the nature of matter). In fact, as we have seen there is much agreement between both on the characterization of the transcendent Form: in this respect, Proclus calling it 'unparticipated' would be little more than a descriptive difference, about which Dodds' observation is right. Furthermore, where commentators like A.C. Lloyd have considered Proclus' participation distinction as a response to the sailcloth difficulty from the Parmenides ${ }^{42}$ Proclus does not directly say so himself. In his commentary on the passage, Proclus notes the absurdity of the imagery lies instead with the division which is implied in sense perception between the Form and the participants ${ }^{43}$ — which is also essentially Plotinus' response. Ultimately the sailcloth metaphor is not where we find Plotinus and Proclus differing on participation, but instead on the question whether participants ontologically acquire distinct properties or not.

\section{Conclusion}

To conclude this paper, we can see that there is a marked agreement, and simultaneous disagreement, between Plotinus and Proclus on participation. Although the latter does not directly critique the former over the framework, Proclus' understanding is instrumental in his explicit attacks on Plotinus over a whole range of issues at the different hierarchical levels: the nature of the One; ${ }^{44}$ the nature of particular souls as descended rather than undescended; the nature of sensible substance; and (as we have seen) the nature of matter.

There are various reasons one can give for the basic divergence on participation, but one may be Proclus wishing to better account for the ontology of plurality at all levels, from the henads below the One to Aristotelian enmattered form. By contrast, Plotinus wishes to emphasize unity to such a degree that plurality is the accidental result. Although this might be an overgeneralization, we can see that both figures' attempt to work with consistent principles for these two contrasting angles, at the same time that they both essentially agree on the priority of unity in participation.

\footnotetext{
${ }^{41}$ See In Parm. 839[x]: 'Hence those who wish to keep matter impassive as it participates in the Forms liken it to a mirror and call the forms in it images or reflections ... The former look to prime matter when keeping it impassive. Since prime matter is simple, it would disappear if it suffered an effect, for what is simple cannot have one part of itself affected and a different part remain unchanged' (trans. Morrow/Dillon). And then Proclus' proposed response, ibid. 840,7-15 (Steel): 'But we might also say that the products of participation are somewhat like the images (eikones) made by the art of painting, or sculpture, or some other technique. For it is by divine craftsmanship that things here are shaped into likenesses of the divine Forms, and this is why the whole sensible cosmos is called a likeness (eikôn) of the intelligible [Tim. 92c]. This analogy is superior to the former kinds [viz. the mirror and wax-seal/stamp analogies] in that it distinguishes the producer from the paradigm, whereas they take these two factors as one' (trans. Morrow/Dillon, modified). See also further down, where Proclus implicitly specifies the unparticipated/participated relation, in $841[\mathrm{x}]$ : 'And finally the factor that is participated comes into contact with the thing that participates, whereas the Forms must be independent of everything and be mixed with nothing else. Also, if the seal should receive a trace from the wax, it would be far from resembling the Forms, whose being is undefiled by taking on anything alien' (trans. Morrow/Dillon).

${ }^{42}$ Lloyd (1990) 69: 'To judge by Proclus, Neoplatonists objected to universal attributes even in subjects, not on the metaphysical ground that they would be inappropriate in the physical world, but on logical objections from the Sail Cloth argument. This argument was used to reject a comfortable compromise whereby only participants and participated entities were called for. Once the need for imparticipables was shown, the participated entities, which were attributes of the participants, were no longer "common natures".' See also Dodds' commentary on ET Prop. 23, where he implies that Proclus is responding to aporia.

${ }^{43}$ In Parm. 864-866.

${ }^{44}$ I.e. Proclus' assertion of the principle of intermediaries between the One and Being.
} 


\section{References}

Caluori, Damian. 2015. Plotinus on the Soul. Cambridge University Press.

Chiaradonna, R. 2014. "Substance." In The Routledge Handbook of Neoplatonism, edited by Svetla Slaveva-Griffin and Pauliina Remes, 216-30. Abingdon: Routledge.

De Haas, Frans A.J. 1997. John Philoponus' New Definition of Prime Matter. Leiden: Brill.

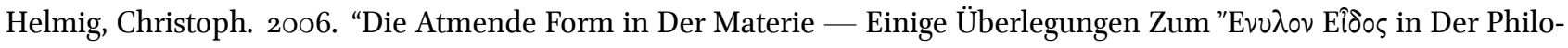
sophie Des Proklos." In Proklos: Methode, Seelenlehre, Metaphysik, edited by Matthias Perkams and Rosa Maria Piccione, 25978. Leiden: Brill.

Karamanolis, George. 2009. "Plotinus on Quality and Immanent Form." In Physics and Philosophy of Nature in Greek Neoplatonism: Proceedings of the European Science Foundation Exploratory Workshop (Il Ciocco, Castelvecchio Pascoli, June 22-24, 2006), edited by Riccardo Chiaradonna and FT Trabattoni, 79-10o. Leiden: Brill.

Lloyd, A.C. 199o. The Anatomy of Neoplatonism. Oxford: Clarendon Press.

Noble, Christopher Isaac. 2013. "How Plotinus' Soul Animates His Body: The Argument for the Soul-Trace at Ennead 4.4.18.1-9." Phronesis 58 (3): 249-79.

Opsomer, Jan. 2001. "Proclus Vs Plotinus on Matter (de Mal. Subs. 30-7)." Phronesis 46 (2): 154-88.

Russi, Chiara. 2009. "Causality and Sensible Objects: A Comparison Between Plotinus and Proclus." In Physics and Philosophy of Nature in Greek Neoplatonism, edited by Riccardo Chiaradonna and Franco Trabattoni, 145-71. Leiden: Brill.

Strange, Steven K. 1992. "Plotinus' Account of Participation in Ennead VI.4-5." Journal of the History of Philosophy 30 (4): 479-96.

Van Riel, Gerd. 2001. "Horizontalism or Verticalism? Proclus Vs Plotinus on the Procession of Matter." Phronesis 46 (2): $129-53$. 